\title{
A Multimodal Approach to the Management of Neuroendocrine Tumour Liver Metastases
}

\author{
Ron Basuroy, ${ }^{1}$ Rajaventhan Srirajaskanthan, ${ }^{2}$ and John K. Ramage, ${ }^{1,2}$ \\ ${ }^{1}$ Department of Gastroenterology and Hepatology, Basingstoke and North Hampshire Foundation Trust, Basingstoke RG24 9NA, UK \\ ${ }^{2}$ Neuroendocrine Tumour Service, Institute of Liver Studies, King's College Hospital, London SE5 9RS, UK
}

Correspondence should be addressed to Ron Basuroy, ronbasuroy@gmail.com

Received 3 August 2011; Accepted 2 December 2011

Academic Editor: Wouter de Herder

Copyright () 2012 Ron Basuroy et al. This is an open access article distributed under the Creative Commons Attribution License, which permits unrestricted use, distribution, and reproduction in any medium, provided the original work is properly cited.

\begin{abstract}
Neuroendocrine tumours (NETs) are often indolent malignancies that commonly present with metastatic disease in the liver. Surgical, locoregional, and systemic treatment modalities are reviewed. A multidisciplinary approach to patient care is suggested to ensure all therapeutic options explored.
\end{abstract}

\section{Introduction}

Neuroendocrine tumours (NETs) are uncommon tumours that can arise anywhere within the body, but predominantly from the gastroenteropancreatic tract. Recent epidemiological evidence suggest that the incidence of all NETs is approximately $3-5$ per 100,000 population per year with a prevalence of 35 per 100,000 population because of slow tumour growth $[1,2]$. Though most NETs are nonfunctional, others secrete peptide hormones that can cause clinical syndromes, like flushing, diarrhoea, bronchospasm and palpitations seen with carcinoid syndrome. The majority of these tumours are indolent, slow growing malignancies, commonly presenting with metastatic disease. The most common site of distant metastases is the liver. Consequently, many therapies are focused at treating the primary and also the metastatic disease in the liver. Due to the indolent nature of most of these tumours, the 5-year survival of patients with metastatic disease at presentation is approximately 50\%. There may have been some improvement in survival from medical and surgical therapies. New molecular-targeted therapies and an aggressive surgical approach to resection of primary and secondary tumours show benefit.

This paper focuses on management of liver metastases of NETs and covers both surgery, locoregional, and systemic therapy. In general, local therapies to the liver should be considered first if disease is confined to the liver. This allows systemic therapies to be given at a later stage if there is extrahepatic spread. Results for liver-directed and systemic therapy of neuroendocrine tumour liver metastases are summarised in Tables 1 and 2, respectively.

\section{Liver-directed Therapies}

Consensus guidance recommends surgery for liver metastases in well-differentiated NETs if complete resection or debulking of $<90 \%$ tumour load is feasible [45]. However, intended curative surgery is only possible in less than $10 \%$ of patients who are diagnosed with hepatic metastases at presentation [3, 46-49]. The distribution of liver metastases affects survival; solitary metastases, isolated metastatic bulk with smaller accompanying deposits, and disseminated metastatic spread have 5-year survival rates of $100 \%, 84 \%$, and $51 \%$, respectively [50].

An aggressive surgical approach to resecting liver metastases is supported by significantly improved actuarial survival in series compared to nonrandomised controls [35]. A number of different surgical approaches are available depending on the distribution of metastases. If primarily unilobar metastases are present, a one-step approach can be adopted. In these cases, resection of the primary plus liver resection can be performed. A two-step surgical approach to bilobar metastases from luminal NETs with resection of the primary, limited resection of left liver lobe metastases, and right portal vein ligation followed by right hepatectomy has been proposed [6]. Overall survival and disease-free rates at 5 years were $94 \%$ and $50 \%$ with this approach. Other 


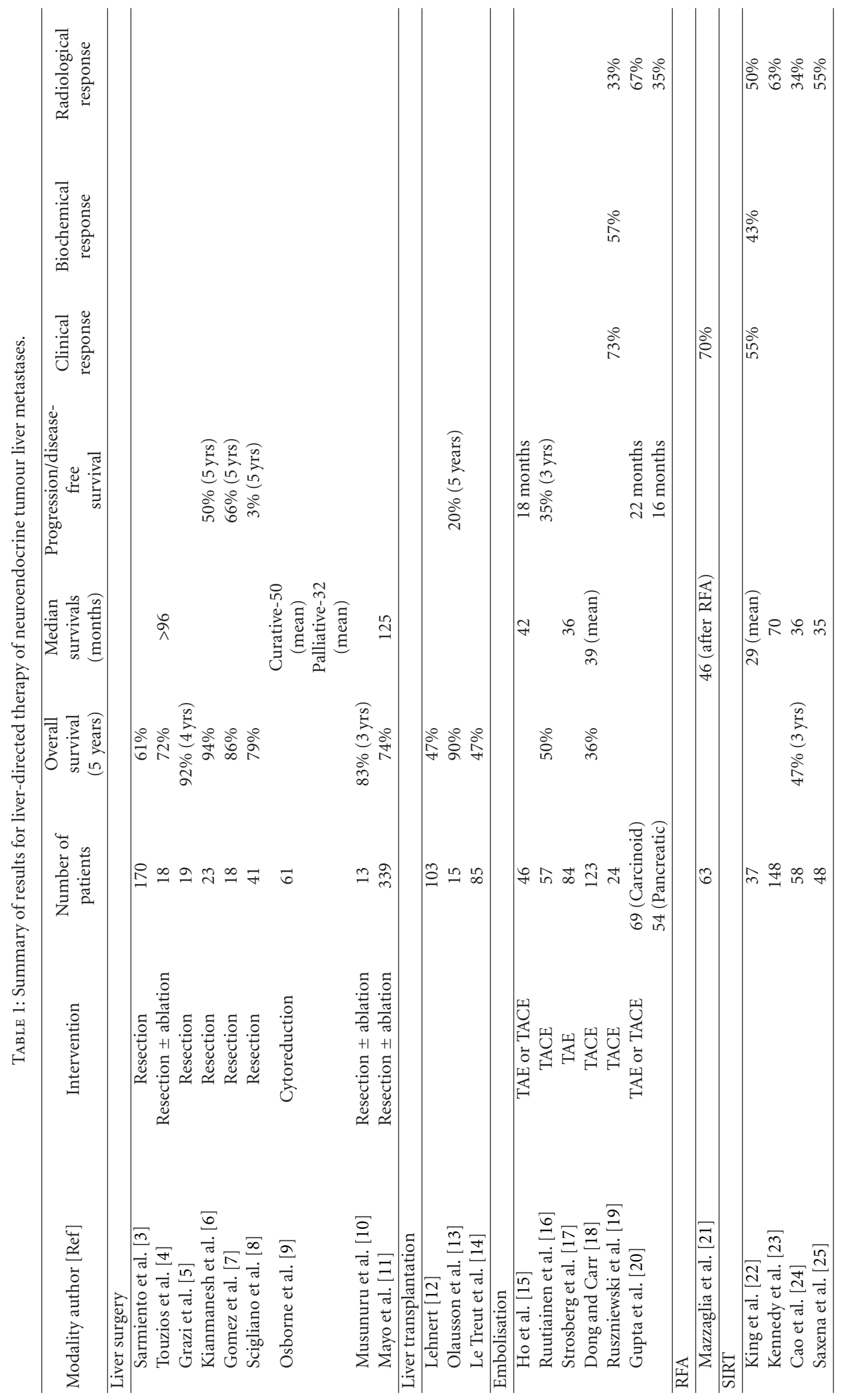




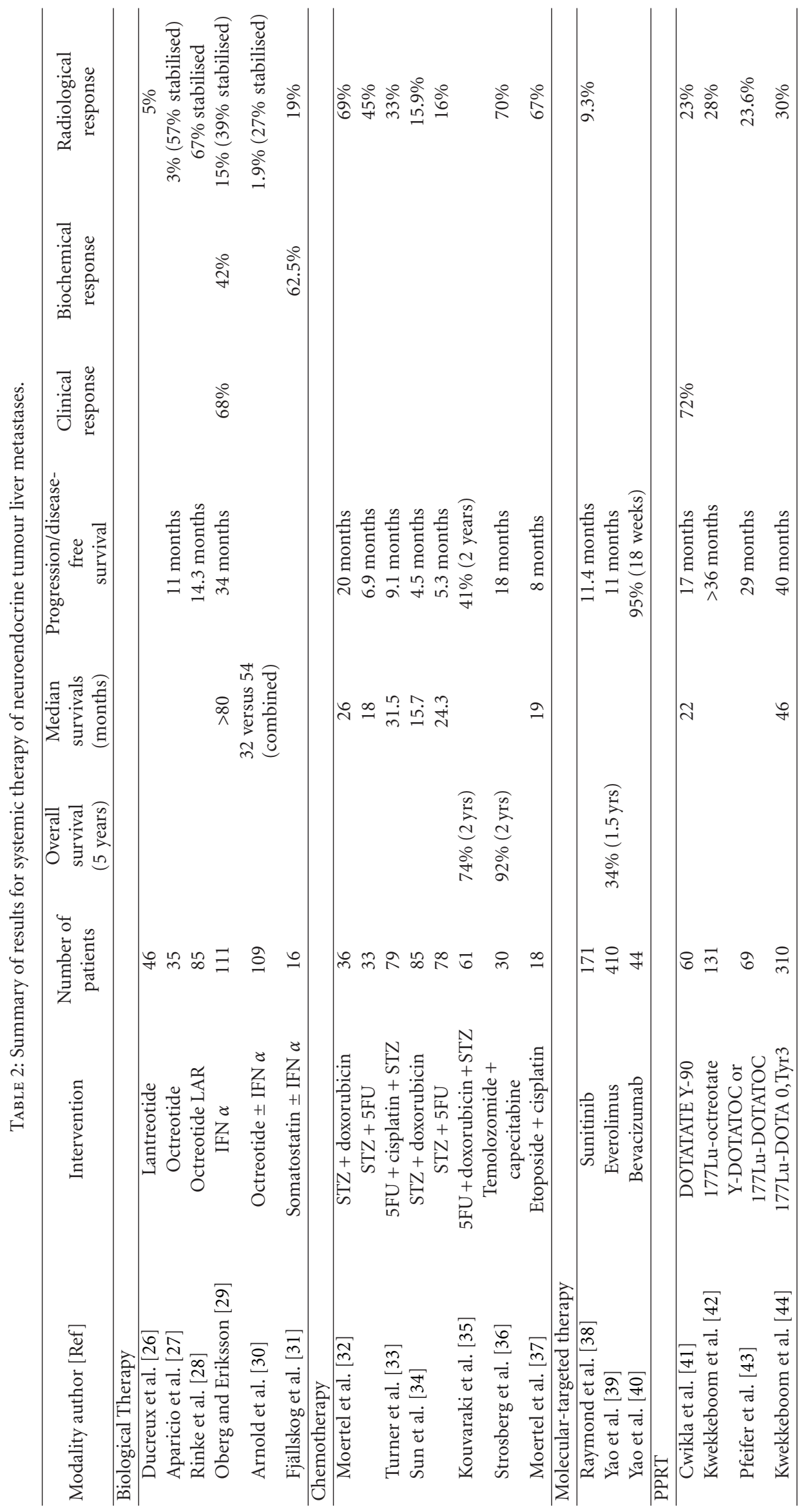


series report a range of overall survival and disease-free rates $[7-9,51]$. A significant improvement in 3-year survival for surgical resection over medical treatment or embolisation has been demonstrated in a study limited by bias. [10]. The completeness of resection, in particular resection margin involvement, is thought to be more important than the number, localization, and size of liver metastases $[7,52,53]$. Histological grade and extrahepatic disease are predictive of overall survival $[54,55]$. Disease has been shown to recur in $78-94 \%$ of patients at 5 years $[3,8,11]$.

After surgery, patients with functioning tumours have prolonged partial or complete symptomatic response rates that can contribute to improved quality of life $[11,56,57]$. Patients with carcinoid tumours have reduced biomarkers (e.g., Chromogranin A and urinary 5-HIAA) after surgery that correlate with symptom relief and disease control [3, 58]. Some rarer functioning syndromes, like those related to PTHrP or VIP secretion, can be improved by debulking surgery [59].

There is no evidence from randomised clinical trials supporting liver surgery, either for curative resection or for debulking in nonresectable disease, over other treatment modalities. Liver surgery only achieved significance in improving survival in univariate but not multivariate analysis [60-62]. Neoadjuvant strategies for downsizing liver metastases or adjuvant chemotherapy following hepatic resection have not yet been subject to controlled clinical trials [63-65].

\subsection{Surgery to Primary Tumour in Metastatic NETs. Recent} guidelines recommend resection of the primary tumour and mesenteric lymph nodes in jejunum/ileum NETs [66-68]. Tumour mass reduction or debulking of primary jejunal and ileal NETs reduces the possibility of bowel ischaemia and obstruction from tumour and mesenteric lymph nodes mass effect even in the context of liver metastases. Resection of the primary tumour has been shown to be an independent positive predictor of survival $(P=0.015)$ and associated with a significantly longer survival than no resection (median survival 7.4 versus 4.0 years; $P<0.01$ ) $[62,69]$. Successful resection of mesenteric metastases and the desmoplastic reaction around the primary site are also associated with a significantly longer survival. Significant reductions in tumour-related symptoms are also seen after primary and mesenteric lymph node resections.

Aggressive surgery to primary tumours and resectable liver metastases in pancreatic NETs is recommended [67, 70]. Resection of pancreatic NETs has been suggested to be associated with significantly improved survival compared to those who did not undergo resection (114 months versus 35 months; $P<.0001$ ) though significant biases may exist in this study [71]. This survival benefit was demonstrated for patients with localized, regional, and metastatic disease with an adjusted odds ratio of 0.48 . Independent predictors of survival after resection of pancreatic NETs include age, grade, presence of distant metastases, tumour functionality, and type of resection [72]. Current guidelines do not recommend surgery to the primary pancreatic tumour in patients with unresectable liver metastases $[70,73]$.
2.2. Transplantation. The role of orthotopic liver transplant is controversial given the demand for donor organs and a lack of clear selection criteria [74]. Patients with debilitating and poorly controlled hormonal syndromes from small intestine or pancreatic NETs are considered for transplantation as symptom relief is seen in $90 \%$ of patients following surgery $[12,13,75-78]$. Five-year recurrence-free rates vary from $25-50 \%$. Overall five-year survival rates are around $50 \%$ but vary according to patient selection $[13,14,79,80]$. Patients presenting with duodenal or pancreatic NET in association with hepatomegaly have poorer outcomes ( $12 \%$ versus $68 \%$ five-year survival rates) [14]. The presence of extensive extrahepatic tumour resected at the time of transplantation is associated with poorer median and five-year survival rates of ten months and 30\%, respectively [12]. Important selection criteria include well-differentiated tumours, low proliferation rate $(\mathrm{Ki}-67<10 \%)$, and regular E-Cadherin staining [81, 82]. The Milan criteria for transplantation include age less than 55 years, low grade carcinoid NET, limited metastatic disease in the liver $(<50 \%)$, previously resected tumours drained only by the portal system (pancreas and mid gut origin NETs), and stable disease for 6 months [83]. Combination treatment with chemotherapeutic agents, chemoembolisation, systemic radiopeptide treatment, and aggressive surgery for recurrence may lead to improved survival rates [84-86].

2.3. Embolisation. NET liver metastases are highly vascular with an arterial supply that if occluded will lead to ischaemia and necrosis. Normal tissue is supplied from the portal vein and preserved during embolisation of hepatic arteries. A catheter is guided to the hepatic artery or branch and material (gelfoam powder, microembospheres, and polyvinyl alcohol particles) released to occlude the vessel in bland embolisation. In chemoembolisation, cytotoxics (like cisplatin, mirplatin, gemcitabine, doxorubicin, streptozocin, and 5-FU) are injected prior to arterial embolisation in order to achieve higher concentrations and prolonged action in necrotic tissue [87-89]. Contraindications to embolisation include occlusion of the portal vein, severe liver dysfunction, and presence of biliary anastomosis. Relative contraindications include tumour burden, renal impairment, and heart disease (including carcinoid heart disease) [90, 91]. A postembolisation syndrome may occur with abdominal pain, vomiting, fever, and rise in transaminases.

Vascular occlusion can achieve reduced hormonal symptoms from NET syndromes, reduced tumour burden, and improved survival in patients who have tried medical therapy and who are not suitable for surgical resection [92-95]. Sequential hepatic artery occlusion can offer prolonged palliation for responsive patients even if performed later in their clinical course $[90,96,97]$.

Median survival rates after transarterial embolisation (TAE) or chemoembolistaion (TACE) in patients with liver metastases is over 3 years with progression-free survival (PFS) of around 18 months [15-18, 98-100]. Clinical response rates of over $90 \%$ are seen following treatment [91]. Intact primary tumour, extensive liver disease, and bone metastases are associated with worse outcomes. 
Embolisation of nonresectable liver metastases often results in disease regression in patients with carcinoid or pancreatic NETs [17, 19]. TACE appears to benefit patients with pancreatic NETs while TAE benefits those with ileal NETs [20]. A small randomized study of TAE versus TACE in all liver NETs has shown no difference in time to progression [101].

2.4. Radiofrequency Ablation (RFA). RFA of oligonodular liver metastases (fewer than 8 ) of less than $5 \mathrm{~cm}$ can result in symptomatic response in $70-80 \%$ of patients with hormonal syndromes for as long as 24 months [21, 63, 102, 103]. Electrical energy is delivered to tissues via a catheter, inserted percutaneously or laparoscopically, which leads to heating and cell death $[104,105]$. Microwave RFA can reduce time required for this procedure. RFA can play an important role in the treatment of carcinoid metastases not suitable for surgical resection and refractory to TAE, improving symptom control, reducing octreotide dependence, and slowing progression in patients [106-108]. Limitations to using RFA include increased numbers and size of liver metastases as well as the detrimental cooling effect of blood flow from neighbouring blood vessels. Local recurrence has been identified in $21.7 \%$ of tumours on CT scans with a mean follow-up of 17 months. Recurrence can be predicted by tumour type and size, ablation margin, and blood vessel proximity [103, 109]. Median survival after starting RFA treatment is 3.9 years [21]. Although RFA may play a promising role in the treatment of liver metastases from NETs, its effect on survival and tumour progression needs to be explored in larger studies. In particular, studies are needed comparing surgical resection with RFA.

2.5. Selective Internal Radiation Therapy (SIRT). Radioembolisation of liver metastases can be achieved with Yttrium90 resin microspheres in patients with disseminated and inoperable liver disease even if previous TAE or TACE has taken place $[22,110]$. (90 Y) microspheres are injected through a percutaneously placed hepatic artery catheter via the femoral or brachial artery. Contraindication to SIRT is similar to those of bland embolisation, vascular involvement such as portal vein thrombosis, severe liver dysfunction, and large tumour burden. Long-term radiologic and biological responses can be achieved with radioembolisation with partial or complete response seen in $63 \%$ $[22,23]$. Median survival varies from 36 to 70 months $[23,24]$. Prognostic factors include radiographic response to treatment, tumour grade, and presence of extrahepatic disease. Patients with hepatic tumour burden of $20-50 \%$ by volume, well-differentiated tumour, female gender, and no extrahepatic disease benefit most from treatment [25]. There is no randomized evidence that radiologic and symptom response rates following SIRT are different from those seen with TACE and TAE.

\section{Systemic Therapies}

3.1. Biological Therapy. Over $70 \%$ of NETs express cellsurface somatostatin receptors that are targeted by synthetic somatostatin analogues. Patients with functional NETs can derive significant symptomatic benefit from the use of somatostatin analogues that suppress the secretion of peptide hormones. Octreotide can provide symptomatic response in up to $85 \%$ of patients and biochemical response in up to $70 \%$ of patients within weeks of commencement $[111,112]$. Patients with NETs undergoing interventional procedures can experience severe symptoms related to the release of vasoactive hormones, like serotonin, that can cause a carcinoid crisis with bronchospasm, tachycardia, and labile blood pressure. This can be ameliorated through the use of octreotide infusions before, during, and after interventional procedures.

Some groups have reported an antiproliferative property of somatostatin analogues [26, 27, 112, 113]. Octreotide LAR has been found to significantly lengthen the time to tumour progression compared to placebo injections (14.3 versus 6 months resp.) [28]. The benefit was seen in both functionally active and inactive tumours. Patients with low hepatic tumour load and resected primary tumour benefited the most from treatment with octreotide LAR. Overall, survival was not an endpoint of this study, consequently; survival benefit from the use of somatostatin analogues has not been confirmed.

Interferon alpha 3-5 megaunits 3-5 times per week have been used with some symptomatic response, but no clear reduction in tumour size or survival benefit [29-31, 114, $115]$. Interferon alpha should be considered as second-line biological therapy after somatostatin analogues.

3.2. Chemotherapy. Systemic chemotherapy has a role in the treatment of pancreatic and high grade NETs. Patient selection and individualized treatment are required to minimize toxicity, maximize response, and improve overall quality of life. The degree of differentiation and tumour grade of NETs can guide management $[116,117]$. Poorly differentiated and high-proliferative tumours (from histological grading like Ki-67 and mitotic index) behave more aggressively but are more sensitive to cytotoxic therapy than well-differentiated and low-proliferative tumours (Ki-67 < 10\%) [33]. Objective response to chemotherapy varies between $25-78 \%$ with progression-free periods between 4-22 months [32, 34, 37, 118-124]. Therefore, it is essential to ensure that chemotherapy is offered to patients who are likely to respond; those with pancreatic NETs, aggressive phenotypes, and high proliferation rates [125]. Biochemical and radiological progression in asymptomatic patients identifies those with rapidly progressive disease and an aggressive phenotype [67]. Response to cytotoxic therapy can be established from radiological-quantified reduction in tumour size, improved biochemical markers as well as improvements in quality of life as measured by health questionnaires [126-128].

Single-agent chemotherapy is seldom used because of limited response rates, toxicity, and poor survival rates. Newer agents like paclitaxel, temozolomide, topotecan, and gemcitabine are not markedly better than older agents like streptozocin, dacarbazine, 5 flourouracil, and doxorubicin when used as monotherapy [121, 126, 129-135]. In patients with pancreatic NET, combination chemotherapy 


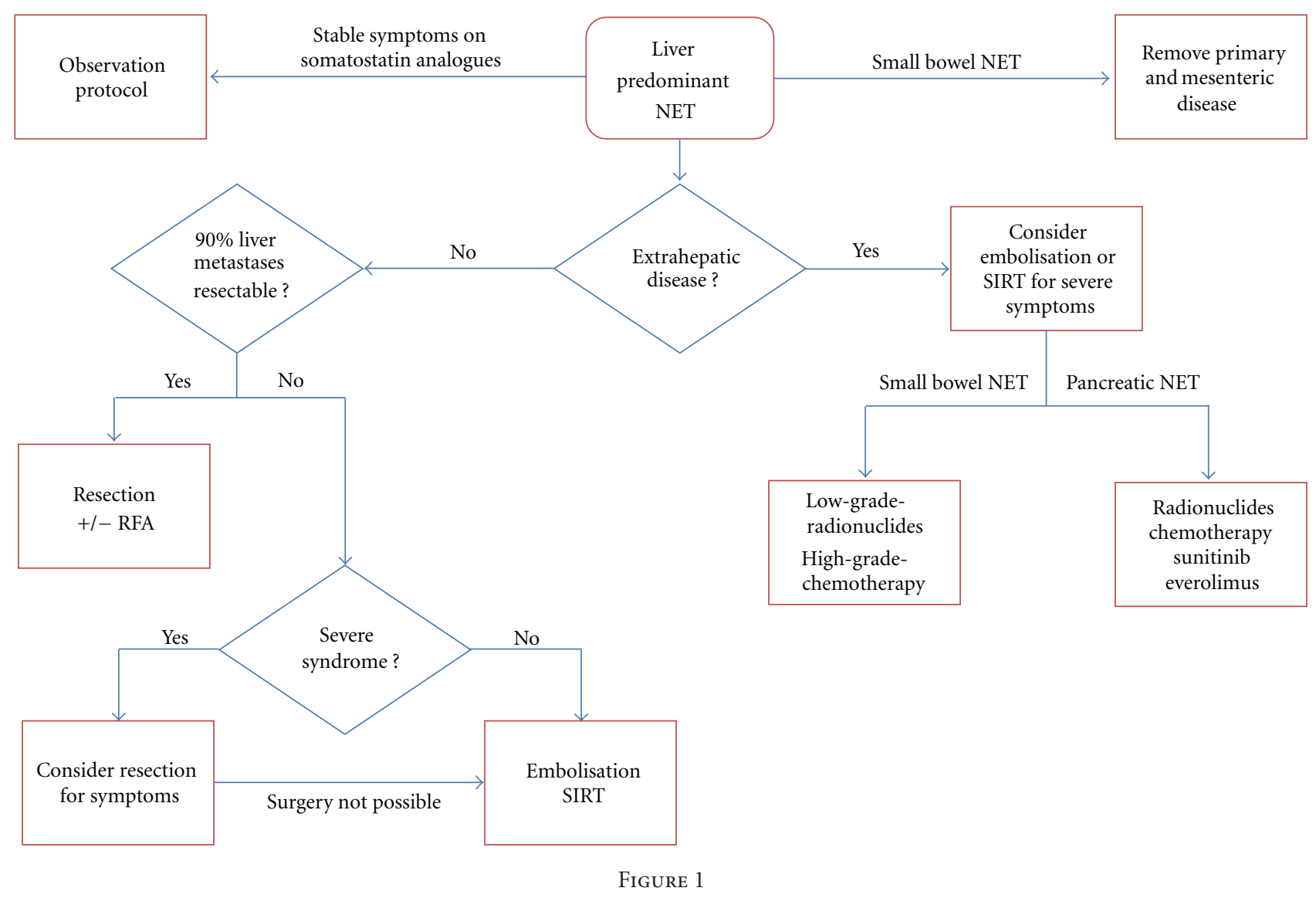

with streptozocin and doxorubicin is superior to streptozocin and 5FU in terms of response rates, time to progression, and overall survival $[32,136,137]$. Response rates from streptozocin and doxorubicin combination treatment vary between 30-70\% [33-35, 138]. Recently, a retrospective analysis of capecitabine and temozolomide combination chemotherapy has demonstrated good response rates, superior to traditional streptozocin-based chemotherapy [36]. In 30 patients treated with capecitabine and temozolomide, response rates of $70 \%$, progression-free survival of 18 months and overall survival of $92 \%$ at 2 years were observed. However, streptozocin-based therapy remains the standard chemotherapy regime for pancreatic NETs given the lack of data from randomised trials demonstrating benefit from other regimes $[36,116,123,139,140]$. Poorly differentiated or anaplastic NETs respond to a combination of cisplatin and etoposide, a regime used in small cell lung cancer $[37,118-$ 120]. Despite chemotherapy, the prognosis remains poor in this group with a 2-year survival between $20-30 \%$.

3.3. Molecular-Targeted Therapies. Novel systemic agents target the molecular mechanisms that are implicated in the pathogenesis of NETs [141, 142].

Sunitinib, a multitargeted tyrosine kinase inhibitor, has activity against a range of molecular targets, including VEGF receptors and platelet-derived growth factor receptors, and has been shown to have antitumour activity in pancreatic
NETs [143]. Median PFS is significantly longer in patients treated with sunitinib over placebo ( 11.4 versus 5.5 months) [38]. Objective response rates and overall survival are also improved with sunitinib treatment. Frequent adverse events encountered include diarrhoea, nausea, vomiting, asthenia, and fatigue.

Everolimus, an oral inhibitor of mammalian target of rapamycin (mTOR), has activity against pancreatic NET tumours through a mechanism of cellular apoptosis and antiangiogenesis $[144,145]$. Median PFS is significantly longer in those treated with everolimus over placebo (11 versus 4.6 months) [39]. Severe adverse events like hyperglycaemia and anaemia were rare, with stomatitis, diarrhoea, and fatigue are more commonly seen.

Vascular endothelial growth factor (VEGF) is overexpressed in NETs and targeted by the ligand monoclonal antibody Bevacizumab [40, 146, 147]. There are reports of clinical benefit when combined with existing chemotherapy treatments [148, 149].

3.4. Peptide Receptor Radionuclide Therapy (PRRT). Somatostatin receptors subtype 2 are expressed in the majority of NETs and confirmed through uptake in octreotide scintigraphy or somatostatin-based PET imaging [150-152]. Betaemitting $90 \mathrm{Y}$ - and $177 \mathrm{Lu}$-labeled somatostatin analogues have been studied in patients with metastatic and inoperable disease [41, 42, 153-156]. The majority of patients develop 
stable disease with the average time to progression of 40 months from commencing therapy. Partial and complete objective responses are seen in up to $30 \%$ of patients with median PFS of over 2 years [43, 157]. From diagnosis, there is a survival benefit of $40-72$ months compared to historical controls [44]. Predictive factors include high tumour uptake on scintigraphy and limited liver metastases. Adverse events include bone marrow and liver toxicity as well as radiation-induced lose of renal function and gastrointestinal disturbance from the use of renoprotective agents [158, 159]. The addition of radiosensitisers like gemcitabine and capecitabine to PPRT may improve clinical outcomes [160, 161]. Alpha-emitting isotopes, such as actinum-225 (225Ac), have a higher cytotoxic activity than beta emitters and may be used in PRRT [162].

MIBG scans are also used to identify patients with metastatic NETs. 131 I-MIBG therapy is associated with significantly improved 5 -year survival rates of $85 \%$ (nonrandomized studies) as well as marked symptomatic and hormonal improvement [163-165]. Symptomatic response predicts improved survival.

\section{Conclusion}

There are a number of treatment modalities available in the management of neuroendocrine tumour liver metastases with a treatment algorithm outlined in Figure 1. Proactive surgical resection, with curative intent or for debulking (cytoreduction), has been shown to improve outcomes and should be pursued initially. In patients with more advanced disease or not amenable to surgical resection, locoregional therapies, like embolisation and SIRT, offer improved outcomes and may downstage disease. Newer systemic therapies, in particular PRRT and molecular targeted therapies, can play a role in patients with extrahepatic and progressive disease. Although there is a lack of robust evidence-based data in the management of patients with metastatic NETs, the future appears more positive with the range of treatment options available. An individualized approach to patient care is needed given the breadth of symptoms and disease, the lack of a validated treatment pathway as well as the indolent nature of NETs. Patient care should be managed under the auspices of a multidisciplinary team to ensure that all treatment options are explored both at diagnosis and followup.

\section{References}

[1] J. C. Yao, M. Hassan, A. Phan et al., "One hundred years after "carcinoid": epidemiology of and prognostic factors for neuroendocrine tumors in 35,825 cases in the United States," Journal of Clinical Oncology, vol. 26, no. 18, pp. 3063-3072, 2008.

[2] I. M. Modlin, K. D. Lye, and M. Kidd, "A 5-decade analysis of 13,715 carcinoid tumors," Cancer, vol. 97, no. 4, pp. 934-959, 2003.

[3] J. M. Sarmiento, G. Heywood, J. Rubin, D. M. Ilstrup, D. M. Nagorney, and F. G. Que, "Surgical treatment of neuroendocrine metastases to the liver: a plea for resection to increase survival," Journal of the American College of Surgeons, vol. 197, no. 1, pp. 29-37, 2003.

[4] J. G. Touzios, J. M. Kiely, S. C. Pitt et al., "Neuroendocrine hepatic metastases: does aggressive management improve survival?” Annals of Surgery, vol. 241, no. 5, pp. 776-785, 2005.

[5] G. L. Grazi, M. Cescon, F. Pierangeli et al., "Highly aggressive policy of hepatic resections for neuroendocrine liver metastases," Hepato-Gastroenterology, vol. 47, no. 32, pp. 481-486, 2000.

[6] R. Kianmanesh, A. Sauvanet, O. Hentic et al., "Two-step surgery for synchronous bilobar liver metastases from digestive endocrine tumors: a safe approach for radical resection," Annals of Surgery, vol. 247, no. 4, pp. 659-665, 2008.

[7] D. Gomez, H. Z. Malik, A. Al-Mukthar et al., "Hepatic resection for metastatic gastrointestinal and pancreatic neuroendocrine tumours: outcome and prognostic predictors," $H P B$, vol. 9, no. 5, pp. 345-351, 2007.

[8] S. Scigliano, R. Lebtahi, F. Maire et al., "Clinical and imaging follow-up after exhaustive liver resection of endocrine metastases: a 15-year monocentric experience," Endocrine-Related Cancer, vol. 16, no. 3, pp. 977-990, 2009.

[9] D. A. Osborne, E. E. Zervos, J. Strosberg et al., "Improved outcome with cytoreduction versus embolization for symptomatic hepatic metastases of carcinoid and neuroendocrine tumors," Annals of Surgical Oncology, vol. 13, no. 4, pp. 572581, 2006.

[10] S. Musunuru, H. Chen, S. Rajpal et al., "Metastatic neuroendocrine hepatic tumors: resection improves survival," Archives of Surgery, vol. 141, no. 10, pp. 1000-1004, 2006.

[11] S. C. Mayo, M. C. de Jong, C. Pulitano et al., "Surgical management of hepatic neuroendocrine tumor metastasis: results from an international multi-institutional analysis," Annals of Surgical Oncology, vol. 17, no. 12, pp. 3129-3136, 2010.

[12] T. Lehnert, "Liver transplantation for metastatic neuroendocrine carcinoma: an analysis of 103 patients," Transplantation, vol. 66, no. 10, pp. 1307-1312, 1998.

[13] M. Olausson, S. Friman, G. Herienius et al., "Orthotopic liver of multivisceral transplantation as treatment of metastatic neuroendocrine tumors," Liver Transplantation, vol. 13, no. 3, pp. 327-333, 2007.

[14] Y. P. Le Treut, E. Grégoire, J. Belghiti et al., "Predictors of long-term survival after liver transplantation for metastatic endocrine tumors: an 85-case French multicentric report," American Journal of Transplantation, vol. 8, no. 6, pp. 12051213, 2008.

[15] A. S. Ho, J. Picus, M. D. Darcy et al., "Long-term outcome after chemoembolization and embolization of hepatic metastatic lesions from neuroendocrine tumors," American Journal of Roentgenology, vol. 188, no. 5, pp. 1201-1207, 2007.

[16] A. T. Ruutiainen, M. C. Soulen, C. M. Tuite et al., "Chemoembolization and bland embolization of neuroendocrine tumor metastases to the liver," Journal of Vascular and Interventional Radiology, vol. 18, no. 7, pp. 847-855, 2007.

[17] J. R. Strosberg, J. Choi, A. B. Cantor, and L. K. Kvols, "Selective hepatic artery embolization for treatment of patients with metastatic carcinoid and pancreatic endocrine tumors," Cancer Control, vol. 13, no. 1, pp. 72-78, 2006.

[18] X. D. Dong and B. I. Carr, "Hepatic artery chemoembolization for the treatment of liver metastases from neuroendocrine tumors: a long-term follow-up in 123 patients," Medical Oncology, vol. 28, supplement 1, pp. 286-290, 2010. 
[19] P. Ruszniewski, P. Rougier, A. Roche et al., "Hepatic arterial chemoembolization in patients with liver metastases of endocrine tumors: a prospective Phase II study in 24 patients," Cancer, vol. 71, no. 8, pp. 2624-2630, 1993.

[20] S. Gupta, M. M. Johnson, R. Murthy et al., "Hepatic arterial embolization and chemoembolization for the treatment of patients with metastatic neuroendocrine tumors: variables affecting response rates and survival," Cancer, vol. 104, no. 8, pp. 1590-1602, 2005.

[21] P. J. Mazzaglia, E. Berber, M. Milas, and A. E. Siperstein, "Laparoscopic radiofrequency ablation of neuroendocrine liver metastases: a 10-year experience evaluating predictors of survival," Surgery, vol. 142, no. 1, pp. 10-19, 2007.

[22] J. King, R. Quinn, D. M. Glenn et al., "Radioembolization with selective internal radiation microspheres for neuroendocrine liver metastases," Cancer, vol. 113, no. 5, pp. 921-929, 2008.

[23] A. S. Kennedy, W. A. Dezarn, P. McNeillie et al., "Radioembolization for unresectable neuroendocrine hepatic metastases using resin 90Y-microspheres: early results in 148 patients," American Journal of Clinical Oncology, vol. 31, no. 3, pp. 271-279, 2008.

[24] C. Q. Cao, T. D. Yan, L. Bester, W. Liauw, and D. L. Morris, "Radioembolization with yttrium microspheres for neuroendocrine tumour liver metastases," British Journal of Surgery, vol. 97, no. 4, pp. 537-543, 2010.

[25] A. Saxena, T. C. Chua, L. Bester, A. Kokandi, and D. L. Morris, "Factors predicting response and survival after yttrium-90 radioembolization of unresectable neuroendocrine tumor liver metastases: a critical appraisal of 48 cases," Annals of Surgery, vol. 251, no. 5, pp. 910-916, 2010.

[26] M. Ducreux, P. Ruszniewski, J. A. Chayvialle et al., "The antitumoral effect of the long-acting somatostatin analog lanreotide in neuroendocrine tumors," American Journal of Gastroenterology, vol. 95, no. 11, pp. 3276-3281, 2000.

[27] T. Aparicio, M. Ducreux, E. Baudin et al., "Antitumour activity of somatostatin analogues in progressive metastatic neuroendocrine tumours," European Journal of Cancer, vol. 37, no. 8, pp. 1014-1019, 2001.

[28] A. Rinke, H. H. Müller, C. Schade-Brittinger et al., "Placebocontrolled, double-blind, prospective, randomized study on the effect of octreotide LAR in the control of tumor growth in patients with metastatic neuroendocrine midgut tumors: a report from the PROMID study group," Journal of Clinical Oncology, vol. 27, no. 28, pp. 4656-4663, 2009.

[29] K. Oberg and B. Eriksson, "The role of interferons in the management of carcinoid tumours," British Journal of Haematology, vol. 79, no. 1, supplement, pp. 74-77, 1991.

[30] R. Arnold, A. Rinke, K.-J. Klose, H.-H. Müller, M. Wied, and K. Zamzow, "Octreotide versus octreotide plus interferonalpha in endocrine gastroenteropancreatic tumors: a randomized trial," Clinical Gastroenterology and Hepatology, vol. 3, no. 8, pp. 761-771, 2005.

[31] M.-L. Fjällskog, A. Sundin, J.-E. Westlin, K. Öberg, E. T. Janson, and B. Eriksson, "Treatment of malignant endocrine pancreatic tumors with a combination of $\alpha$-interferon and somatostatin analogs," Medical Oncology, vol. 19, no. 1, pp. 35-42, 2002.

[32] C. G. Moertel, M. Lefkopoulo, S. Lipsitz, R. G. Hahn, and D. Klaassen, "Streptozocin-doxorubicin, streptozocin-fluorouracil, or chlorozotocin in the treatment of advanced isletcell carcinoma," New England Journal of Medicine, vol. 326, no. 8, pp. 519-523, 1992.
[33] N. C. Turner, S. J. Strauss, D. Sarker et al., "Chemotherapy with 5-fluorouracil, cisplatin and streptozocin for neuroendocrine tumours," British Journal of Cancer, vol. 102, no. 7, pp. 1106-1112, 2010.

[34] W. Sun, S. Lipsitz, P. Catalano, J. A. Mailliard, and D. G. Haller, "Phase II/III study of doxorubicin with fluorouracil compared with streptozocin with fluorouracil or dacarbazine in the treatment of advanced carcinoid tumors. Eastern Cooperative Oncology Group Study E1281," Journal of Clinical Oncology, vol. 23, no. 22, pp. 4897-4904, 2005.

[35] M. A. Kouvaraki, J. A. Ajani, P. Hoff et al., "Fluorouracil, doxorubicin, and streptozocin in the treatment of patients with locally advanced and metastatic pancreatic endocrine carcinomas," Journal of Clinical Oncology, vol. 22, no. 23, pp. 4762-4771, 2004.

[36] J. R. Strosberg, R. L. Fine, J. Choi et al., "First-line chemotherapy with capecitabine and temozolomide in patients with metastatic pancreatic endocrine carcinomas," Cancer, vol. 117, no. 2, pp. 268-275, 2011.

[37] C. G. Moertel, L. K. Kvols, M. J. O’Connell, and J. Rubin, "Treatment of neuroendocrine carcinomas with combined etoposide and cisplatin: evidence of major therapeutic activity in the anaplastic variants of these neoplasms," Cancer, vol. 68, no. 2, pp. 227-232, 1991.

[38] E. Raymond, L. Dahan, J.-L. Raoul et al., "Sunitinib malate for the treatment of pancreatic neuroendocrine tumors," New England Journal of Medicine, vol. 364, no. 6, pp. 501-513, 2011.

[39] J. C. Yao, M. H. Shah, T. Ito et al., "Everolimus for advanced pancreatic neuroendocrine tumors," New England Journal of Medicine, vol. 364, no. 6, pp. 514-523, 2011.

[40] J. C. Yao, A. Phan, P. M. Hoff et al., "Targeting vascular endothelial growth factor in advanced carcinoid tumor: a random assignment phase ii study of depot octreotide with bevacizumab and pegylated interferon alfa-2b," Journal of Clinical Oncology, vol. 26, no. 8, pp. 1316-1323, 2008.

[41] J. B. Cwikla, A. Sankowski, N. Seklecka et al., "Efficacy of radionuclide treatment DOTATATE Y-90 in patients with progressive metastatic gastroenteropancreatic neuroendocrine carcinomas (GEP-NETs): a phase II study," Annals of Oncology, vol. 21, no. 4, pp. 787-794, 2009.

[42] D. J. Kwekkeboom, J. J. Teunissen, W. H. Bakker et al., "Radiolabeled somatostatin analog [177Lu-DOTA0, Tyr3] octreotate in patients with endocrine gastroenteropancreatic tumors," Journal of Clinical Oncology, vol. 23, no. 12, pp. 2754-2762, 2005.

[43] A. K. Pfeifer, T. Gregersen, H. Gronbaek, C. P. Hansen, J. Muller-Brand, and K. Herskind Bruun, "Peptide receptor radionuclide therapy with Y-DOTATOC and (177)LuDOTATOC in advanced neuroendocrine tumors: results from a Danish cohort treated in Switzerland," Neuroendocrinology, vol. 93, no. 3, pp. 189-196, 2011.

[44] D. J. Kwekkeboom, W. W. De Herder, B. L. Kam, C. H. Van Eijck, M. Van Essen, and P. P. Kooij, "Treatment with the radiolabeled somatostatin analog [177Lu- DOTA0,Tyr3] octreotate: toxicity, efficacy, and survival," Journal of Clinical Oncology, vol. 26, no. 13, pp. 2124-2130, 2008.

[45] T. Steinmüller, R. Kianmanesh, M. Falconi et al., "Consensus guidelines for the management of patients with liver metastases from digestive (neuro)endocrine tumors: foregut, midgut, hindgut, and unknown primary," Neuroendocrinology, vol. 87, no. 1, pp. 47-62, 2007.

[46] F. G. Que, J. M. Sarmiento, and D. M. Nagorney, "Hepatic surgery for metastatic gastrointestinal neuroendocrine 
tumors," Advances in Experimental Medicine and Biology, vol. 574, pp. 43-56, 2006.

[47] F. G. Que, J. M. Sarmiento, and D. M. Nagorney, "Hepatic surgery for metastatic gastrointestinal neuroendocrine tumors," Cancer Control, vol. 9, no. 1, pp. 67-79, 2002.

[48] R. S. Chamberlain, D. Canes, K. T. Brown et al., "Hepatic neuroendocrine metastases: does intervention alter outcomes?" Journal of the American College of Surgeons, vol. 190, no. 4, pp. 432-445, 2000.

[49] J. A. Norton, R. S. Warren, M. G. Kelly et al., "Aggressive surgery for metastatic liver neuroendocrine tumors," Surgery, vol. 134, no. 6, pp. 1057-1065, 2003.

[50] A. Frilling, J. Li, E. Malamutmann, K. W. Schmid, A. Bockisch, and C. E. Broelsch, "Treatment of liver metastases from neuroendocrine tumours in relation to the extent of hepatic disease," British Journal of Surgery, vol. 96, no. 2, pp. 175-184, 2009.

[51] J. M. Sarmiento and F. G. Que, "Hepatic surgery for metastases from neuroendocrine tumors," Surgical Oncology Clinics of North America, vol. 12, no. 1, pp. 231-242, 2003.

[52] D. Elias, P. Lasser, M. Ducreux et al., "Liver resection (and associated extrahepatic resections) for metastatic welldifferentiated endocrine tumors: a 15-year single center prospective study," Surgery, vol. 133, no. 4, pp. 375-382, 2003.

[53] H. Nave, E. Mössinger, H. Feist, H. Lang, and H. R. Raab, "Surgery as primary treatment in patients with liver metastases from carcinoid tumors: a retrospective, unicentric study over 13 years," Surgery, vol. 129, no. 2, pp. 170-175, 2001.

[54] A. Saxena, T. C. Chua, A. Sarkar et al., "Progression and survival results after radical hepatic metastasectomy of indolent advanced neuroendocrine neoplasms (NENs) supports an aggressive surgical approach," Surgery, vol. 149, no. 2, pp. 209-220, 2011.

[55] C. S. Cho, D. M. Labow, L. Tang et al., "Histologic grade is correlated with outcome after resection of hepatic neuroendocrine neoplasms," Cancer, vol. 113, no. 1, pp. 126-134, 2008.

[56] F. G. Que, D. M. Nagorney, K. P. Batts, L. J. Linz, and L. K. Kvols, "Hepatic resection for metastatic neuroendocrine carcinomas," American Journal of Surgery, vol. 169, no. 1, pp. 36-43, 1995.

[57] A. J. Chambers, J. L. Pasieka, E. Dixon, and O. Rorstad, "The palliative benefit of aggressive surgical intervention for both hepatic and mesenteric metastases from neuroendocrine tumors," Surgery, vol. 144, no. 4, pp. 645-653, 2008.

[58] E. H. Jensen, L. Kvols, J. M. McLoughlin et al., "Biomarkers predict outcomes following cytoreductive surgery for hepatic metastases from functional carcinoid tumors," Annals of Surgical Oncology, vol. 14, no. 2, pp. 780-785, 2007.

[59] R. Srirajaskanthan, M. McStay, C. Toumpanakis, T. Meyer, and M. E. Caplin, "Parathyroid hormone-related peptidesecreting pancreatic neuroendocrine tumours: case series and literature review," Neuroendocrinology, vol. 89, no. 1, pp. 48$55,2009$.

[60] K. S. Gurusamy, R. Ramamoorthy, D. Sharma, and B. R. Davidson, "Liver resection versus other treatments for neuroendocrine tumours in patients with resectable liver metastases," Cochrane Database of Systematic Reviews, no. 2, Article ID CD007060, 2009.

[61] K. S. Gurusamy, V. Pamecha, D. Sharma, and B. R. Davidson, "Palliative cytoreductive surgery versus other palliative treatments in patients with unresectable liver metastases from gastro-entero-pancreatic neuroendocrine tumours,"
Cochrane Database of Systematic Reviews, no. 1, Article ID CD007118, 2009.

[62] A. Ahmed, G. Turner, B. King et al., "Midgut neuroendocrine tumours with liver metastases: results of the UKINETS study," Endocrine-Related Cancer, vol. 16, no. 3, pp. 885-894, 2009.

[63] J. Eriksson, P. Stålberg, A. Nilsson et al., "Surgery and radiofrequency ablation for treatment of liver metastases from midgut and foregut carcinoids and endocrine pancreatic tumors," World Journal of Surgery, vol. 32, no. 5, pp. 930938, 2008.

[64] O. Stoeltzing, E. Huber, M. Loss et al., "Staged surgery with neoadjuvant 90Y-DOTATOC therapy for down-sizing synchronous bilobular hepatic metastases from a neuroendocrine pancreatic tumor," Langenbeck's Archives of Surgery, vol. 395, no. 2, pp. 185-192, 2010.

[65] R. Whitney, C. Tatum, M. Hahl et al., "Safety of hepatic resection in metastatic disease to the liver after yttrium-90 therapy," Journal of Surgical Research, vol. 166, no. 2, pp. 236240, 2011.

[66] B. Eriksson, G. Klöppel, E. Krenning et al., "Consensus guidelines for the management of patients with digestive neuroendocrine tumors-well-differentiated jejunalileal tumor/carcinoma," Neuroendocrinology, vol. 87, no. 1, pp. 8-19, 2007.

[67] O. H. Clark, A. B. Benson III, J. D. Berlin, M. A. Choti, G. M. Doherty, and P. F. Engstrom, "NCCN Clinical Practice Guidelines in Oncology: neuroendocrine tumors," The Journal of the National Comprehensive Cancer Network, vol. 7, no. 7, pp. 712-747, 2009.

[68] J. P. Boudreaux, D. S. Klimstra, M. M. Hassan et al., "The NANETS consensus guideline for the diagnosis and management of neuroendocrine tumors: well-differentiated neuroendocrine tumors of the jejunum, ileum, appendix, and cecum," Pancreas, vol. 39, no. 6, pp. 753-766, 2010.

[69] P. Hellman, T. Lundström, U. Öhrvall et al., "Effect of surgery on the outcome of midgut carcinoid disease with lymph node and liver metastases," World Journal of Surgery, vol. 26, no. 8, pp. 991-997, 2002.

[70] M. Falconi, U. Plöckinger, D. J. Kwekkeboom et al., "Well-differentiated pancreatic nonfunctioning tumors/carcinoma," Neuroendocrinology, vol. 84, no. 3, pp. 196-211, 2007.

[71] J. S. Hill, J. T. McPhee, T. P. McDade, Z. Zhou, M. E. Sullivan, and G. F. Whalen, "Pancreatic neuroendocrine tumors: the impact of surgical resection on survival," Cancer, vol. 115, no. 4, pp. 741-751, 2009.

[72] K. Y. Bilimoria, M. S. Talamonti, J. S. Tomlinson et al., "Prognostic score predicting survival after resection of pancreatic neuroendocrine tumors: analysis of 3851 patients," Annals of Surgery, vol. 247, no. 3, pp. 490-500, 2008.

[73] M. H. Kulke, L. B. Anthony, D. L. Bushnell et al., "NANETS treatment guidelines: well-differentiated neuroendocrine tumors of the stomach and pancreas," Pancreas, vol. 39, no. 6, pp. 735-752, 2010.

[74] E. Gregoire and Y. P. Le Treut, "Liver transplantation for primary or secondary endocrine tumors," Transplant International, vol. 23, no. 7, pp. 704-711, 2010.

[75] Y. P. Le Treut, J. R. Delpero, B. Dousset et al., "Results of liver transplantation in the treatment of metastatic neuroendocrine tumors: a 31-case French multicentric report," Annals of Surgery, vol. 225, no. 4, pp. 355-364, 1997. 
[76] W. C. Blonski, K. R. Reddy, A. Shaked, E. Siegelman, and D. C. Metz, "Liver transplantation for metastatic neuroendocrine tumor: a case report and review of the literature," World Journal of Gastroenterology, vol. 11, no. 48, pp. 7676$7683,2005$.

[77] A. Frilling, X. Rogiers, W. T. Knofel, and C. E. Broelsch, "Liver transplantation for metastatic carcinoid tumors," Digestion, vol. 55, no. 3, pp. 104-106, 1994.

[78] D. Routley, J. K. Ramage, J. McPeake, K. C. Tan, and R. Williams, "Orthotopic liver transplantation in the treatment of metastatic neuroendocrine tumors of the liver," Liver Transplantation and Surgery, vol. 1, no. 2, pp. 118-121, 1995.

[79] H. Lang, H. J. Schlitt, H. Schmidt et al., "Total hepatectomy and liver transplantation for metastatic neuroendocrine tumors of the pancreas-a single center experience with ten patients," Langenbeck's Archives of Surgery, vol. 384, no. 4, pp. 370-377, 1999.

[80] F. G. I. van Vilsteren, E. S. Baskin-Bey, D. M. Nagorney et al., "Liver transplantation for gastroenteropancreatic neuroendocrine cancers: defining selection criteria to improve survival," Liver Transplantation, vol. 12, no. 3, pp. 448-456, 2006.

[81] J. Rosenau, M. J. Bahr, R. Von Wasielewski et al., "Ki67, e-cadherin, and p53 as prognostic indicators of long-term outcome after liver transplantation for metastatic neuroendocrine tumors," Transplantation, vol. 73, no. 3, pp. 386-394, 2002.

[82] H. Ahlman, S. Friman, C. Cahlin et al., "Liver transplantation for treatment of metastatic neuroendocrine tumors," Annals of the New York Academy of Sciences, vol. 1014, pp. 265-269, 2004.

[83] V. Mazzaferro, A. Pulvirenti, and J. Coppa, "Neuroendocrine tumors metastatic to the liver: how to select patients for liver transplantation?" Journal of Hepatology, vol. 47, no. 4, pp. 460-466, 2007.

[84] J. A. Fernández, R. Robles, C. Marín et al., "Role of liver transplantation in the management of metastatic neuroendocrine tumors," Transplantation Proceedings, vol. 35, no. 5, pp. 1832-1833, 2003.

[85] A. Frilling, M. Malago, F. Weber et al., "Liver transplantation for patients with metastatic endocrine tumors: single-center experience with 15 patients," Liver Transplantation, vol. 12, no. 7, pp. 1089-1096, 2006.

[86] M. Martin, D. Tarara, Y. M. Wu et al., "Intrahepatic arterial chemoembolization for hepatocellular carcinoma and metastatic neuroendocrine tumors in the era of liver transplantation," American Surgeon, vol. 62, no. 9, pp. 724731, 1996.

[87] Y. H. Kim, J. A. Ajani, C. Humberto Carrasco et al., "Selective hepatic arterial chemoembolization for liver metastases in patients with carcinoid tumor or islet cell carcinoma," Cancer Investigation, vol. 17, no. 7, pp. 474-478, 1999.

[88] T. J. Vogl, T. Gruber, N. N. N. Naguib, R. Hammerstingl, and N. E. A. Nour-Eldin, "Liver metastases of neuroendocrine tumors: treatment with hepatic transarterial chemotherapy using two therapeutic protocols," American Journal of Roentgenology, vol. 193, no. 4, pp. 941-947, 2009.

[89] J. Iwazawa, S. Ohue, K. Yasumasa, and T. Mitani, "Transarterial chemoembolization with miriplatin-lipiodol emulsion for neuroendocrine metastases of the liver," World Journal of Radiology, vol. 2, no. 12, pp. 468-471, 2010.

[90] B. K. Eriksson and E. G. Larsson, "Liver embolizations of patients with malignant neuroendocrine gastrointestinal tumors," Cancer, vol. 83, no. 11, pp. 2293-2301, 1998.
[91] A. Roche, B. V. Girish, T. De Baere et al., "Prognostic factors for chemoembolization in liver metastasis from endocrine tumors," Hepato-Gastroenterology, vol. 51, no. 60, pp. 1751$1756,2004$.

[92] J. Nazario and S. Gupta, "Transarterial liver-directed therapies of neuroendocrine hepatic metastases," Seminars in Oncology, vol. 37, no. 2, pp. 118-126, 2010.

[93] C. H. Carrasco, V. P. Chuang, and S. Wallace, "Apudomas metastatic to the liver: treatment by hepatic artery embolization," Radiology, vol. 149, no. 1, pp. 79-83, 1983.

[94] J. G. Drougas, L. B. Anthony, T. K. Blair, R. R. Lopez, J. K. Wright, and W. C. Chapman, "Hepatic artery chemoembolization for management of patients with advanced metastatic carcinoid tumors," American Journal of Surgery, vol. 175, no. 5, pp. 408-412, 1998.

[95] H. Hajarizadeh, K. Ivancev, C. R. Mueller, W. S. Fletcher, and E. A. Woltering, "Effective palliative treatment of metastatic carcinoid tumors with intra-arterial chemotherapy/chemoembolization combined with octreotide acetate," American Journal of Surgery, vol. 163, no. 5, pp. 479-483, 1992.

[96] J. A. Ajani, C. H. Carrasco, C. Charnsangavej, N. A. Samaan, B. Levin, and S. Wallace, "Islet cell tumors metastatic to the liver: effective palliation by sequential hepatic artery embolization," Annals of Internal Medicine, vol. 108, no. 3, pp. 340-344, 1988.

[97] C. Swärd, V. Johanson, E. Nieveen Van Dijkum et al., "Prolonged survival after hepatic artery embolization in patients with midgut carcinoid syndrome," British Journal of Surgery, vol. 96, no. 5, pp. 517-521, 2009.

[98] D. Christante, S. Pommier, B. Givi, and R. Pommier, "Hepatic artery chemoinfusion with chemoembolization for neuroendocrine cancer with progressive hepatic metastases despite octreotide therapy," Surgery, vol. 144, no. 6, pp. 885894, 2008.

[99] C. Loewe, M. Schindl, M. Cejna, B. Niederle, J. Lammer, and S. Thurnher, "Permanent transarterial embolization of neuroendocrine metastases of the liver using cyanoacrylate and lipiodol: assessment of mid- and long-term results," American Journal of Roentgenology, vol. 180, no. 5, pp. 13791384, 2003.

[100] A. Roche, B. V. Girish, T. de Baère et al., "Trans-catheter arterial chemoembolization as first-line treatment for hepatic metastases from endocrine tumors," European Radiology, vol. 13, no. 1, pp. 136-140, 2003.

[101] P. Ruszniewski, ENETS; Lisbon, Portugal, 2011.

[102] T. J. Vogl, N. N. N. Naguib, S. Zangos, K. Eichler, A. Hedayati, and N. E. A. Nour-Eldin, "Liver metastases of neuroendocrine carcinomas: interventional treatment via transarterial embolization, chemoembolization and thermal ablation," European Journal of Radiology, vol. 72, no. 3, pp. 517-528, 2009.

[103] E. Berber and A. Siperstein, "Local recurrence after laparoscopic radiofrequency ablation of liver tumors: an analysis of 1032 tumors," Annals of Surgical Oncology, vol. 15, no. 10, pp. 2757-2764, 2008.

[104] A. E. Siperstein, S. J. Rogers, P. D. Hansen, and A. Gitomirsky, "Laparoscopic thermal ablation of hepatic neuroendocrine tumor metastases," Surgery, vol. 122, no. 6, pp. 1147-1155, 1997.

[105] A. E. Siperstein and E. Berber, "Cryoablation, percutaneous alcohol injection, and radiofrequency ablation for treatment of neuroendocrine liver metastases," World Journal of Surgery, vol. 25, no. 6, pp. 693-696, 2001. 
[106] A. Siperstein, A. Garland, K. Engle et al., "Laparoscopic radiofrequency ablation of primary and metastatic liver tumors: technical considerations," Surgical Endoscopy, vol. 14, no. 4, pp. 400-405, 2000.

[107] F. J. Wessels and S. R. Schell, "Radiofrequency ablation treatment of refractory carcinoid hepatic metastases," Journal of Surgical Research, vol. 95, no. 1, pp. 8-12, 2001.

[108] I. S. Tait, S. M. Yong, and S. A. Cuschieri, "Laparoscopic in situ ablation of liver cancer with cryotherapy and radiofrequency ablation," British Journal of Surgery, vol. 89, no. 12, pp. 1613-1619, 2002.

[109] A. Siperstein, A. Garland, K. Engle et al., "Local recurrence after laparoscopic radiofrequency thermal ablation of hepatic tumors," Annals of Surgical Oncology, vol. 7, no. 2, pp. 106$113,2000$.

[110] R. Murthy, P. Kamat, R. Nunez et al., "Yttrium-90 microsphere radioembolotherapy of hepatic metastatic neuroendocrine carcinomas after hepatic arterial embolization," Journal of Vascular and Interventional Radiology, vol. 19, no. 1, pp. 145-151, 2008.

[111] M. B. Jacobsen and L. E. Hanssen, "Clinical effects of octreotide compared to placebo in patients with gastrointestinal neuroendocrine tumours. Report on a double-blind, randomized trial," Journal of Internal Medicine, vol. 237, no. 3, pp. 269-275, 1995.

[112] K. Öberg, "Chemotherapy and biotherapy in the treatment of neuroendocrine tumours," Annals of Oncology, vol. 12, no. 2, supplement, pp. S111-S114, 2001.

[113] H. Imam, B. Eriksson, A. Lukinius et al., "Induction of apoptosis in neuroendocrine tumors of the digestive system during treatment with somatostatin analogs," Acta Oncologica, vol. 36, no. 6, pp. 607-614, 1997.

[114] N. Fazio, F. de Braud, G. Delle Fave, and K. Öberg, "Interferon- $\alpha$ and somatostatin analog in patients with gastroenteropancreatic neuroendocrine carcinoma: single agent or combination?" Annals of Oncology, vol. 18, no. 1, pp. 1319, 2007.

[115] S. Faiss, U.-F. Pape, M. Böhmig et al., "Prospective, randomized, multicenter trial on the antiproliferative effect of lanreotide, interferon alfa, and their combination for therapy of metastatic neuroendocrine gastroenteropancreatic tumors-the International Lanreotide and Interferon Alfa Study Group," Journal of Clinical Oncology, vol. 21, no. 14, pp. 2689-2696, 2003.

[116] E. Bajetta, L. Catena, G. Procopio et al., "Are capecitabine and oxaliplatin (XELOX) suitable treatments for progressing lowgrade and high-grade neuroendocrine tumours?" Cancer Chemotherapy and Pharmacology, vol. 59, no. 5, pp. 637-642, 2007.

[117] E. Vilar, R. Salazar, J. Pérez-García, J. Cortes, K. Öberg, and J. Tabernero, "Chemotherapy and role of the proliferation marker Ki-67 in digestive neuroendocrine tumors," Endocrine-Related Cancer, vol. 14, no. 2, pp. 221-232, 2007.

[118] C. Toumpanakis, T. Meyer, and M. E. Caplin, "Cytotoxic treatment including embolization/chemoembolization for neuroendocrine tumours," Best Practice and Research, vol. 21, no. 1, pp. 131-144, 2007.

[119] J. D. Hainsworth, D. R. Spigel, S. Litchy, and F. Anthony Greco, "Phase II trial of paclitaxel, carboplatin, and etoposide in advanced poorly differentiated neuroendocrine carcinoma: a minnie pearl cancer research network study," Journal of Clinical Oncology, vol. 24, no. 22, pp. 3548-3554, 2006.

[120] M.-L. H. Fjällskog, D. P. K. Granberg, S. L. V. Welin et al., "Treatment with cisplatin and etoposide in patients with neuroendocrine tumors," Cancer, vol. 92, no. 5, pp. 1101$1107,2001$.

[121] M. H. Kulke, H. Kim, J. W. Clark et al., "A phase II trial of gemcitabine for metastatic neuroendocrine tumors," Cancer, vol. 101, no. 5, pp. 934-939, 2004.

[122] M. H. Kulke, B. Wu, D. P. Ryan et al., "A phase II trial of irinotecan and cisplatin in patients with metastatic neuroendocrine tumors," Digestive Diseases and Sciences, vol. 51, no. 6, pp. 1033-1038, 2006.

[123] M. H. Kulke, K. Stuart, P. C. Enzinger et al., "Phase II study of temozolomide and thalidomide in patients with metastatic neuroendocrine tumors," Journal of Clinical Oncology, vol. 24, no. 3, pp. 401-406, 2006.

[124] E. Rivera and J. A. Ajani, "Doxorubicin, streptozocin, and 5fluorouracil chemotherapy for patients with metastatic isletcell carcinoma," American Journal of Clinical Oncology, vol. 21, no. 1, pp. 36-38, 1998.

[125] R. Arnold, A. Rinke, C. Schmidt, and L. Hofbauer, "Endocrine tumours of the gastrointestinal tract: chemotherapy," Best Practice \& Research Clinical Gastroenterology, vol. 19, no. 4, pp. 649-656, 2005.

[126] G. Kaltsas, J. J. Mukherjee, P. N. Plowman, and A. B. Grossman, "The role of chemotherapy in the nonsurgical management of malignant neuroendocrine tumours," Clinical Endocrinology, vol. 55, no. 5, pp. 575-587, 2001.

[127] A. H. G. Davies, G. Larsson, J. Ardill, E. Friend, L. Jones, and M. Falconi, "Development of a disease-specific quality of life questionnaire module for patients with gastrointestinal neuroendocrine tumours," European Journal of Cancer, vol. 42, no. 4, pp. 477-484, 2006.

[128] M. Q. Hatton and N. S. Reed, "Chemotherapy for neuroendocrine tumors: the Beatson Oncology Centre experience," Clinical Oncology, vol. 9, no. 6, pp. 385-389, 1997.

[129] R. M. Bukowski, C. M. Tangen, R. F. Peterson et al., "Phase II trial of dimethyltriazenoimidazole carboxamide in patients with metastatic carcinoid. A Southwest Oncology Group study," Cancer, vol. 73, no. 5, pp. 1505-1508, 1994.

[130] S. M. Ansell, H. C. Pitot, P. A. Burch, L. K. Kvols, M. R. Mahoney, and J. Rubin, "A phase II study of highdose paclitaxel in patients with advanced neuroendocrine tumors," Cancer, vol. 91, no. 8, pp. 1543-1548, 2001.

[131] S. M. Ansell, M. R. Mahoney, E. M. Green, and J. Rubin, "Topotecan in patients with advanced neuroendocrine tumors: a phase II study with significant hematologic toxicity," American Journal of Clinical Oncology, vol. 27, no. 3, pp. 232-235, 2004.

[132] M. H. Kulke, H. Kim, K. Stuart et al., "A phase II study of docetaxel in patients with metastatic carcinoid tumors," Cancer Investigation, vol. 22, no. 3, pp. 353-359, 2004.

[133] C. G. Moertel, J. A. Hanley, and L. A. Johnson, "Streptozocin alone compared with streptozocin plus fluorouracil in the treatment of advanced islet-cell carcinoma," New England Journal of Medicine, vol. 303, no. 21, pp. 1189-1194, 1980.

[134] R. K. Ramanathan, A. Cnaan, R. G. Hahn, P. P. Carbone, and D. G. Haller, "Phase II trial dacarbazine (DTIC) in advanced pancreatic islet cell carcinoma. Study of the Eastern Cooperative Oncology Group-E6282," Annals of Oncology, vol. 12, no. 8, pp. 1139-1143, 2001.

[135] S. Ekeblad, A. Sundin, E. T. Janson et al., "Temozolomide as monotherapy is effective in treatment of advanced malignant neuroendocrine tumors," Clinical Cancer Research, vol. 13, no. 10, pp. 2986-2991, 2007. 
[136] M. A. Gonzalez, S. Biswas, L. Clifton, and P. G. Corrie, "Treatment of neuroendocrine tumours with infusional 5fluorouracil, folinic acid and streptozocin," British Journal of Cancer, vol. 89, no. 3, pp. 455-456, 2003.

[137] P. F. Engstrom, P. T. Lavin, and C. G. Moertel, "Streptozocin plus fluorouracil versus doxorubicin therapy for metastatic carcinoid tumorr," Journal of Clinical Oncology, vol. 2, no. 11, pp. 1255-1259, 1984.

[138] T. Delaunoit, M. Ducreux, V. Boige et al., "The doxorubicinstreptozotocin combination for the treatment of advanced well-differentiated pancreatic endocrine carcinoma: a judicious option?" European Journal of Cancer, vol. 40, no. 4, pp. 515-520, 2004.

[139] G. D. L. Lopes Jr., A. Chiappori, G. Simon et al., "Phase I study of carboplatin in combination with gemcitabine and irinotecan in patients with solid tumors: preliminary evidence of activity in small cell and neuroendocrine carcinomas," Cancer, vol. 109, no. 7, pp. 1413-1419, 2007.

[140] M. Ghosn, F. Farhat, J. Kattan et al., "FOLFOX-6 combination as the first-line treatment of locally advanced and/or metastatic pancreatic cancer," American Journal of Clinical Oncology, vol. 30, no. 1, pp. 15-20, 2007.

[141] J. A. Gilbert, L. J. Adhikari, R. V. Lloyd et al., "Molecular markers for novel therapies in neuroendocrine (carcinoid) tumors," Endocrine-Related Cancer, vol. 17, no. 3, pp. 623636, 2010.

[142] J. C. Yao, "Molecular targeted therapy for carcinoid and isletcell carcinoma," Best Practice and Research, vol. 21, no. 1, pp. 163-172, 2007.

[143] M. H. Kulke, H. J. Lenz, N. J. Meropol et al., "Activity of sunitinib in patients with advanced neuroendocrine tumors," Journal of Clinical Oncology, vol. 26, no. 20, pp. 3403-3410, 2008.

[144] K. Zitzmann, E. N. De Toni, S. Brand et al., "The novel mTOR inhibitor RAD001 (everolimus) induces antiproliferative effects in human pancreatic neuroendocrine tumor cells," Neuroendocrinology, vol. 85, no. 1, pp. 54-60, 2007.

[145] J. C. Yao, C. Lombard-Bohas, E. Baudin et al., "Daily oral everolimus activity in patients with metastatic pancreatic neuroendocrine tumors after failure of cytotoxic chemotherapy: a phase II trial," Journal of Clinical Oncology, vol. 28, no. 1, pp. 69-76, 2010.

[146] G. Christofori, P. Naik, and D. Hanahan, "Vascular endothelial growth factor and its receptors, flt-1 and flk-1, are expressed in normal pancreatic islets and throughout islet cell tumorigenesis," Molecular Endocrinology, vol. 9, no. 12, pp. 1760-1770, 1995.

[147] B. Terris, J. Y. Scoazec, L. Rubbia et al., "Expression of vascular endothelial growth factor in digestive neuroendocrine tumours," Histopathology, vol. 32, no. 2, pp. 133-138, 1998.

[148] D. P. Lindholm, B. Eriksson, and D. Granberg, "Response to temozolomide and bevacizumab in a patient with poorly differentiated neuroendocrine carcinoma," Medical Oncology, In press.

[149] S. Takeuchi, R. Honma, J. Taguchi et al., "A case of high-grade neuroendocrine carcinoma that improved with bevacizumab plus modified FOLFOX6 as the fourth-line chemotherapy," Case Reports in Oncology, vol. 4, no. 2, pp. 260-266, 2011.

[150] I. Virgolini, V. Ambrosini, J. B. Bomanji et al., "Procedure guidelines for PET/CT tumour imaging with 68Ga-DOTAconjugated peptides: 68Ga-DOTA-TOC, 68Ga-DOTA-NOC, 68Ga-DOTA-TATE," European Journal of Nuclear Medicine and Molecular Imaging, vol. 37, no. 10, pp. 2004-2010, 2010.
[151] D. J. Kwekkeboom, E. P. Krenning, R. Lebtahi, P. Komminoth, B. Kos-Kudła, and W. W. De Herder, "ENETS consensus guidelines for the standards of care in neuroendocrine tumors: peptide receptor radionuclide therapy with radiolabeled somatostatin analogs," Neuroendocrinology, vol. 90, no. 2, pp. 220-226, 2009.

[152] D. J. Kwekkeboom, J. Mueller-Brand, G. Paganelli et al., "Overview of results of peptide receptor radionuclide therapy with 3 radiolabeled somatostatin analogs," Journal of Nuclear Medicine, vol. 46, no. 1, supplement, pp. 62S-66S, 2005.

[153] M. Van Essen, E. P. Krenning, B. L. R. Kam, M. De Jong, R. Valkema, and D. J. Kwekkeboom, "Peptide-receptor radionuclide therapy for endocrine tumors," Nature Reviews Endocrinology, vol. 5, no. 7, pp. 382-393, 2009.

[154] M. Van Essen, E. P. Krenning, M. De Jong, R. Valkema, and D. J. Kwekkeboom, "Peptide receptor radionuclide therapy with radiolabelled somatostatin analogues in patients with somatostatin receptor positive tumours," Acta Oncologica, vol. 46, no. 6, pp. 723-734, 2007.

[155] F. Forrer, R. Valkema, D. J. Kwekkeboom, M. de Jong, and E. P. Krenning, "Neuroendocrine tumors. Peptide receptor radionuclide therapy," Best Practice \& Research, vol. 21, no. 1, pp. 111-129, 2007.

[156] D. J. Kwekkeboom, W. W. de Herder, C. H. J. van Eijck et al., "Peptide receptor radionuclide therapy in patients with gastroenteropancreatic neuroendocrine tumors," Seminars in Nuclear Medicine, vol. 40, no. 2, pp. 78-88, 2010.

[157] L. Bodei, G. Pepe, and G. Paganelli, "Peptide receptor radionuclide therapy (PRRT) of neuroendocrine tumors with somatostatin analogues," European Review for Medical and Pharmacological Sciences, vol. 14, no. 4, pp. 347-351, 2010.

[158] D. L. Bushnell Jr., T. M. O’Dorisio, M. S. O’Dorisio et al., "90Y-edotreotide for metastatic carcinoid refractory to octreotide," Journal of Clinical Oncology, vol. 28, no. 10, pp. 1652-1659, 2010.

[159] R. Valkema, S. A. Pauwels, L. K. Kvols et al., "Long-term follow-up of renal function after peptide receptor radiation therapy with 90Y-DOTA0,Tyr3-octreotide and $177 \mathrm{Lu}-$ DOTA0,Tyr3-octreotate," Journal of Nuclear Medicine, vol. 46, no. 1, pp. 83S-91S, 2005.

[160] P. G. Claringbold, P. A. Brayshaw, R. A. Price, and J. H. Turner, "Phase II study of radiopeptide 177Lu-octreotate and capecitabine therapy of progressive disseminated neuroendocrine tumours," European Journal of Nuclear Medicine and Molecular Imaging, vol. 38, no. 2, pp. 302-311, 2011.

[161] T. K. Nayak, R. W. Atcher, E. R. Prossnitz, and J. P. Norenberg, "Enhancement of somatostatin-receptor-targeted 177Lu[DOTA0-Tyr3]-octreotide therapy by gemcitabine pretreatment-mediated receptor uptake, up-regulation and cell cycle modulation," Nuclear Medicine and Biology, vol. 35, no. 6, pp. 673-678, 2008.

[162] M. Miederer, G. Henriksen, A. Alke et al., "Preclinical evaluation of the $\alpha$-particle generator nuclide 225Ac for somatostatin receptor radiotherapy of neuroendocrine tumors," Clinical Cancer Research, vol. 14, no. 11, pp. 3555-3561, 2008.

[163] J. J. Mukherjee, G. A. Kaltsas, N. Islam et al., "Treatment of metastatic carcinoid tumours, phaeochromocytoma, paraganglioma and medullary carcinoma of the thyroid with 131i-meta-iodobenzylguanidine (131I-mIBG)," Clinical Endocrinology, vol. 55, no. 1, pp. 47-60, 2001.

[164] G. Kaltsas, M. Korbonits, E. Heintz et al., "Comparison of somatostatin analog and meta-iodobenzylguanidine 
radionuclides in the diagnosis and localization of advanced neuroendocrine tumors," Journal of Clinical Endocrinology and Metabolism, vol. 86, no. 2, pp. 895-902, 2001.

[165] S. D. Safford, R. E. Coleman, J. P. Gockerman et al., "Iodine131 metaiodobenzylguanidine treatment for metastic carcinoid: results in 98 patients," Cancer, vol. 101, no. 9, pp. 19871993, 2004. 


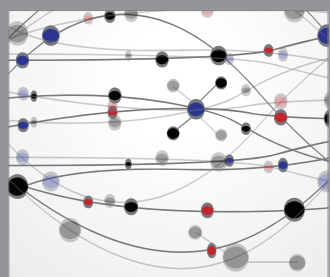

The Scientific World Journal
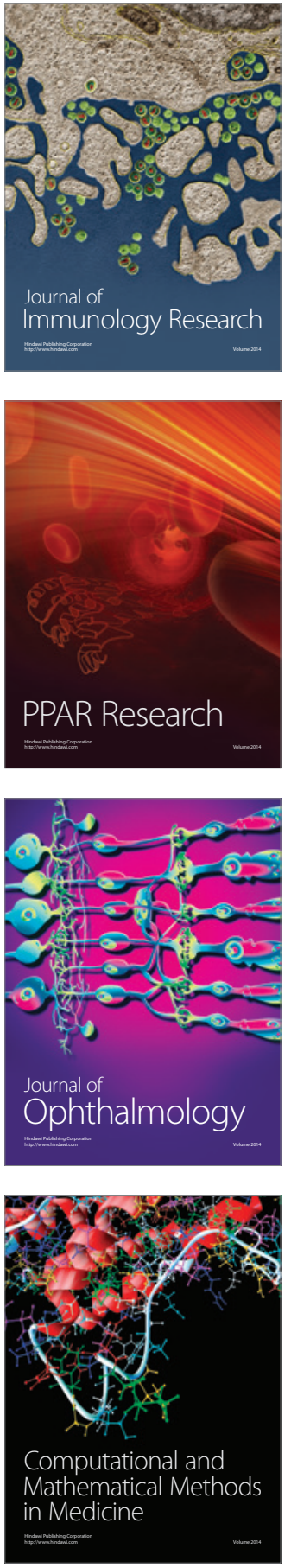

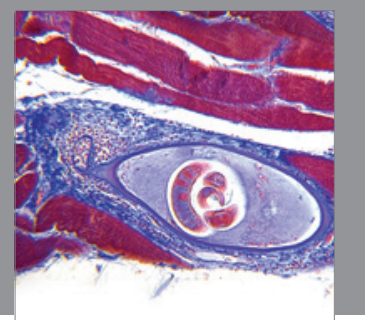

Gastroenterology

Research and Practice
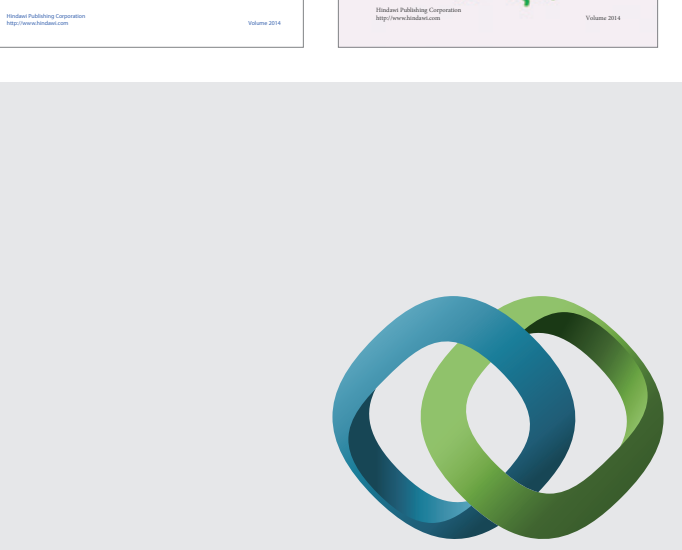

\section{Hindawi}

Submit your manuscripts at

http://www.hindawi.com
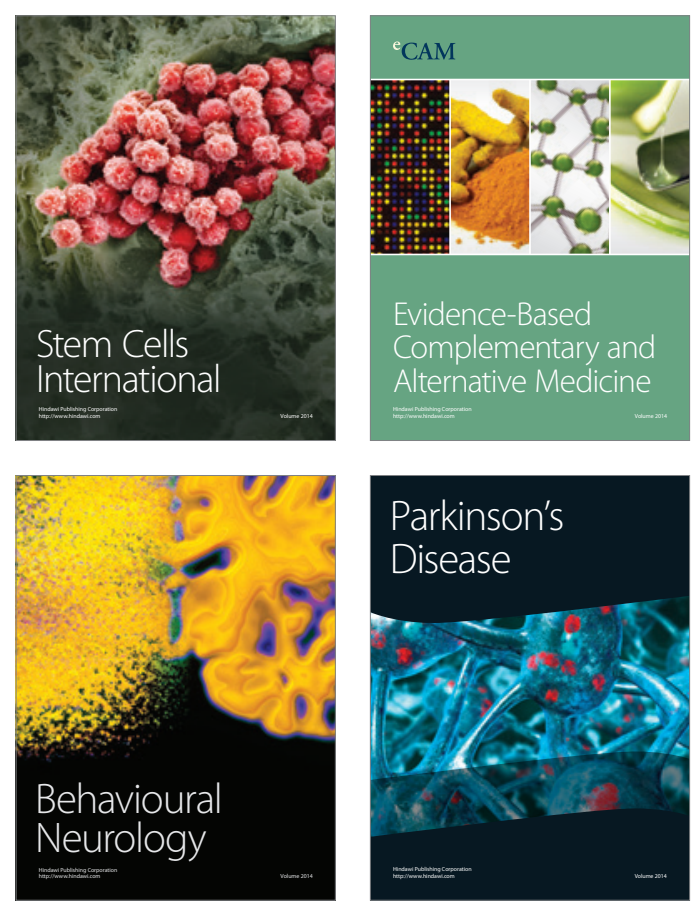

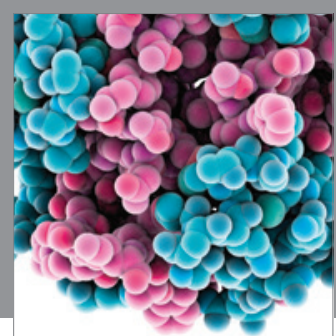

Journal of
Diabetes Research

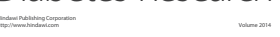

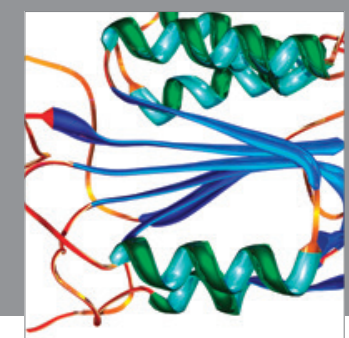

Disease Markers
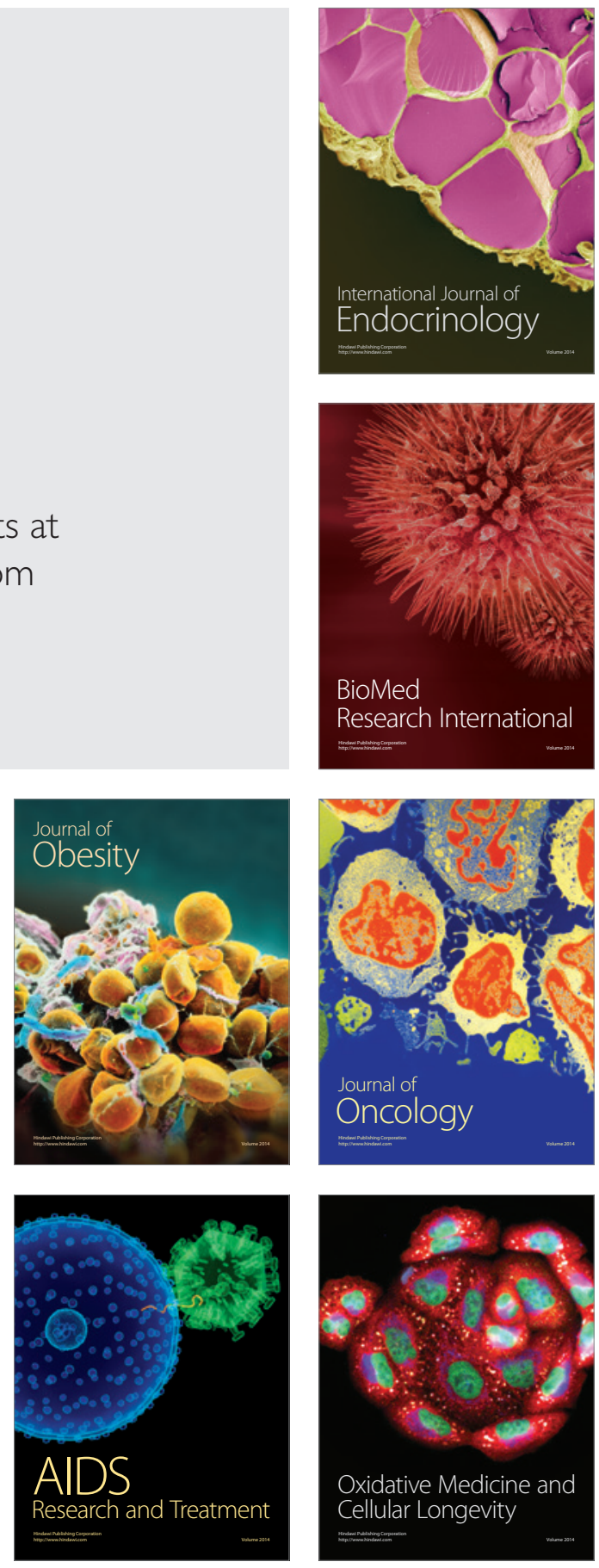